Mal J Nutr 27(2): 233-246, 2021

\title{
Comparison of anthropometric profile, bone-related parameters, biochemical parameters, functional capacity, and vitamin D status - A study on postmenopausal Malaysian women
}

\author{
Mitra Soma $\mathbf{R}^{1^{*}}$ \& Abidin Nurdiana $\mathbf{Z}^{1,2}$ \\ ${ }^{1}$ School of Biosciences, Faculty of Science and Engineering, University of Nottingham \\ Malaysia; ${ }^{2}$ Lifestyle Science Cluster, Advanced Medical and Dental Institute, \\ Universiti Sains Malaysia, Malaysia
}

\begin{abstract}
Introduction: The optimal level of total 25(OH)D in Malaysian postmenopausal women that is necessary to ameliorate the combined effects of decreased bone mineral and muscle mass, and increase in adiposity, as seen in osteosarcopenic obesity, is unknown. Given that these are common pathologies existing in bone, muscle and excess fat-related disorders, this study investigated the association between body composition, functional capacity and total 25(OH)D levels. Methods: This was a cross-sectional study involving 117 postmenopausal Malaysian women aged 50-88 years. Total 25(OH)D was analysed by chemiluminescent microparticle immunoassay CMIA on Siemens ${ }^{\circledR}$ platforms. Bone mineral was measured by broadband ultrasound attenuation. Functional performance was assessed using modified components of short physical performance battery test. Statistical analysis was performed using the Statistical Package for Social Sciences (SPSS Version 25.0). Results: Overall, $47 \%$ women were vitamin D deficient; $3 \%$ had none, $22 \%$ had one, $65 \%$ had two, and $10 \%$ had all three adverse body composition indicators (osteosarcopenic obesity). Individuals without any adverse body composition indicator had higher total $25(\mathrm{OH})$ $\mathrm{D}(74.7 \pm 7.0 \mathrm{nmol} / \mathrm{L}, p=0.004)$ compared to all the other groups $[1(53.0 \pm 3.8 \mathrm{nmol} / \mathrm{L})$; $2(48.7 \pm 1.9 \mathrm{nmol} / \mathrm{L})$ and $3(58.3 \pm 5.4 \mathrm{nmol} / \mathrm{L})]$. The single inflection point (ROC curve) for total 25(OH)D in predicting osteosarcopenic obesity was $58.9 \mathrm{nmol} / \mathrm{L}$. Conclusion: Higher vitamin D levels were associated with lower body fat, enhanced bone quality, and improved functional capacity. Maintaining vitamin D levels above $>58.9 \mathrm{nmol} / \mathrm{L}$ may protect Malaysian postmenopausal women against the combined pathologies of bone, muscle and excess fat.
\end{abstract}

Keywords: Vitamin D, osteosarcopenic obesity, postmenopausal, Malaysian women

\section{INTRODUCTION}

Malaysia is expected to reach the status of an ageing nation by 2030, wherein $15 \%$ of the population would be aged 60 years and above (United Nations
Library, 2017). Ageing is associated with a decrease in bone mineral (Riggs et al., 1981) and muscle mass (Novak, 1972), and an increase in adiposity (Fukagawa, Bandini \& Young, 2017). A decline

\footnotetext{
*Corresponding author: Mitra Soma R

The University of Nottingham Malaysia, Jalan Broga, 43500 Semenyih, Selangor Darul Ehsan, Malaysia Tel: +6(03)8725 3433; Fax: +6(03)8924 8018
}

Email: soma.mitra@nottingham.edu.my

doi: https: / / doi.org/10.31246/mjn-2020-0080 
in physical capacity associated with normal ageing can be attributed to the decline in muscle mass and a reduction in muscle strength (Larsson, Grimby \& Karlsson, 2017). The loss of muscle mass with ageing, termed sarcopenia (Evans, 2011), along with its associated loss in muscle strength, increases the risk of fracture at various skeletal sites. The consequence is reduced mobility and a poor quality of life in advanced age.

Furthermore, a decline in bone mineral may be aggravated in individuals with obesity and those with obesity and sarcopenia combined, compared to individuals suffering from osteopenia/osteoporosis alone (Ormsbee et al., 2014). A combination of adverse interrelationships in body composition is hypothesised to manifest in osteosarcopenic obesity (OSO), a term coined to depict the concurrent occurrence of these three phenotypes - osteopenia/osteoporosis, sarcopenia, and obesity (Ormsbee et al., 2014).

The mechanical interactions between bone and muscle are well established, and a growing body of research suggests a common pathology in bone and musclerelated disorders (Gunton et al., 2015). Increase in adiposity also exacerbates the loss of bone and muscle mass (Ormsbee et al., 2014). OSO may lead to functional impairment and increases the risk of falls, fractures, and morbidity (Ilich et al., 2014).

OSO is defined as T-score $\leq-1.0$, appendicular skeletal muscle mass index $(A S M M I) \leq 5.41 \mathrm{~kg} / \mathrm{m}^{2}\left(20^{\text {th }}\right.$ percentile of ASMMI of the study population), and percent body fat $\geq 32 \%$ (Ilich, Kelly \& Inglis, 2016). Interestingly, serum levels of 25-hydroxyvitamin D $(25$ (OH)D $)$ have been shown to have a significant association with adiposity, bone and muscle-related disorders, which manifest as osteopenia/osteoporosis, sarcopenia, and obesity (Han et al., 2014; Plawecki \& Chapman-Novakofski,
2010). It is well documented that severe vitamin $\mathrm{D}$ deficiency is associated with proximal muscle weakness, which is thought to be associated with secondary hyperparathyroidism and induced hypophosphatemia (Larsson et al., 2017). It is widely accepted that total serum 25(OH)D $\left(\mathrm{D}_{2}\right.$ plus $\left.\mathrm{D}_{3}\right)$ concentration of $<50 \mathrm{nmol} / \mathrm{L}$ represents vitamin D deficiency (IOM, 2011, Bischoff-Ferrari et al., 2006). There is a dearth of information on the relationship between vitamin $\mathrm{D}$ status of individuals with OSO.

The aim of this study was to investigate the association between OSO, body composition, functional capacity, and total 25(OH)D concentrations in postmenopausal Malaysian women. To the best of our knowledge, this is the first study that investigated the relationship between the indices of vitamin $\mathrm{D}$ status and OSO in a group of postmenopausal Malaysian women living in and around the town of Semenyih, Malaysia.

\section{SUBJECTS AND METHODS}

\section{Study population}

A total of 117 apparently healthy postmenopausal Malaysian women aged $50-88$ years were recruited at random through advertisements and flyers that were distributed at schools, community centres, senior citizen clubs, residential areas, and religious centres around the town of Semenyih from April 2017 - March 2019. Postmenopausal was defined as having no menstrual period, bleeding, or spotting during the 12 months prior to enrolment. Interested participants completed a validated and structured health and lifestyle questionnaire, which included questions on ethnic background, past diseases, family history of past diseases, physical activity level, and substance abuse (Aguilar-Farias, 2016; The North American Menopause Society, 2005). 
Consumption of calcium and vitamin D supplements, as well as daily servings of milk were recorded. Use of sunscreen was also recorded.

Apparently healthy and interested participants were screened for eligibility with the following inclusion criteria: (i) a woman, (ii) citizen of Malaysia (of Malay, Indian or Chinese ethnicity), (iii) postmenopausal (no menstrual period, bleeding, or spotting in the 12 consecutive months prior to enrolment). Exclusion criteria included: (i) inability to stand for height, weight, and gait speed assessments, (ii) presence of artificial limbs and/or metal implants, (iii) severe cardiac, pulmonary, or musculoskeletal disorders, (iv) severe cognitive impairment or any disability that makes communication impossible, (v) presence of terminal illness, (vi) on hormone replacement therapy, vii) on medications for anti-convulsant, cholesterolaemia, hypoglycaemia, and psychiatric disorders.

\section{Ethics approval and consent to participate}

This study was conducted according to the guidelines laid down in the Declaration of Helsinki and all procedures involving human subjects were reviewed and approved by the Science and Engineering Research Ethics Committee, University of Nottingham Malaysia (SEREC-NZA051016). Written informed consent was requested and obtained from all willing participants.

\section{Measurement of anthropometric parameters}

Height of individual was measured barefoot with a standard height rod (SECA 217, SECA GmbH \& Co., Hamburg, Germany). Body composition including weight, fat mass $(\mathrm{kg})$, skeletal muscle mass $(\mathrm{kg})$, fat-free mass $(\mathrm{kg})$, and body fat percent (\%) of individuals were measured using a body composition analyser DSM-BIA (InBody 230, Seoul, Korea). Body mass index (BMI) was calculated by using the formula, weight in kilograms divided by the square of height in meters $\left(\mathrm{kg} / \mathrm{m}^{2}\right)$. Waist circumference (WC) was measured at the midpoint between the lower margin of palpable rib and the top of iliac crest, while hip circumference was measured at the widest portion of the buttocks (WHO, 2008). Waist-hip ratio was calculated using the ratio of the circumference of the waist to the hip.

\section{Appendicular skeletal muscle mass index (ASMMI)}

ASMMI was computed from the sum of muscle mass of the four limbs, adjusted for height $\left(\mathrm{kg} /\right.$ height $\left.^{2}\right)$ (InBody 230, Seoul, Korea). A threshold of $5.41 \mathrm{~kg} /$ $\mathrm{m}^{2}$ was used to define OSO (Ilich et al., 2016).

\section{Muscle strength}

Muscle strength was determined by handgrip strength and was measured on both hands using a handgrip dynamometer (JAMAR Hydraulic Hand Dynamometer ${ }^{\circledR}$ Model PC-5030 J 1, USA). Subjects were seated with shoulders adducted and neutrally rotated, elbow flexed at $90^{\circ}$, forearm in neutral, and wrist between 0 and $30^{\circ}$ of dorsiflexion. Grip strength was measured twice at each hand, and the higher of the two values was used in the analysis (Fess \& Moran, 1981).

\section{Calcaneal broadband ultrasound measurements}

Broadband ultrasound attenuation (BUA) measurement of the calcaneus was determined by contact ultrasound sonometry using SAHARA clinical bone sonometer (Hologic Inc, Waltham, MA, USA). All data were collected by the same operator. Participants were measured from April 2017 - March 2019 and as close as practically possible to the time 
of blood sampling for markers of vitamin D status. The foot of the participant was placed in the foot well with ultrasound gel applied on either side of the heel. The foot was then strapped to the footrest. A button was switched on for the emission and receiver probes to close in on the heel. The ultrasound waves emitted from the emission probes through the bone was sensed by the receiver probe. Calcaneal ultrasound measurements were recorded by the data controller. The ultrasound sonometer was calibrated at the start of each session using a 'phantom'. Precision of the instrument was monitored on the heel of the same individual and the $\mathrm{CV}$ was calculated to be $4.1 \%$. Results were recorded as BUA $(\mathrm{dB} / \mathrm{MHz})$, speed of sound (SOS) $(\mathrm{m} / \mathrm{s})$, bone mineral density (BMD) (g/ $\mathrm{cm}^{2}$ ), T-Scores [the number of standard deviation $(S D)$ units above or below the average of young adults], and $Z$-scores (the number of SD units above or below the average of age-matched individuals). Both $\mathrm{T}$ - and $Z$-scores were based on the Hong Kong Chinese Female reference trace of the manufacturer, the closest reference group to the study population.

\section{Functional performance}

Short physical performance battery (SPPB) test

Functional performance was assessed using modified components of SPPB test (Ilich et al., 2016). The tests are described below:

\section{One-leg stance}

Participant was asked to stand on one leg while lifting the contralateral limb, for up to 30 seconds. This was performed on both the right and left legs. The test was stopped when the participant touched any surface or lowered the contralateral limb to the ground or, ultimately, at the end of 30 seconds. The mean value of the right and left legs was documented as the final score (Shin et al., 2014).

\section{Gait speed}

Gait speed was measured by timing a 6-meter normal walk. The 6-meter course was marked by two cones or pieces of tape. Participants were allowed to use a cane or any other walking device they normally use when walking.

\section{Sit-to-stand chair test}

Participants were asked to sit in an armless chair, cross their arms over their chest, with back straight and feet flat on the floor. Participants were then asked to rise from the chair and sit down again. This cycle was repeated for 30 seconds. The number of consecutive, chair sit-tostand cycles completed was recorded, with the last time the participant sat down in the chair being the final count.

\section{Blood collection and biochemical analysis (total 25(OH)D, iPTH, calcium, albumin)}

Fasting blood samples were collected from $8 \mathrm{am}$ to $10 \mathrm{am}$ by a trained phlebotomist, processed and stored at $-80^{\circ} \mathrm{C}$ until analysis. Blood serum was collected using yellow-topped plasma tubes (SST) and plasma was collected using lavendertopped plasma tubes (EDTA as additive). The total 25(OH)D concentration was analysed by chemiluminescent microparticle immunoassay CMIA on Siemens $^{\circledR}$ platforms, Agilent, USA. Serum albumin level was analysed by using BCG Dye bonding on ADVIA $^{\circledR} 2400$ Clinical Chemistry System, Siemens Healthcare GmbH, Germany. Serum intact parathyroid hormone (iPTH) level was analysed using 2-site sandwich microparticle immunoassay from $\quad$ Siemens $^{\circledR}$ ADVIA ${ }^{\circledR}$ Centaur XP immunoassay system, Siemens Healthcare $\mathrm{GmbH}$, Germany. Serum calcium level was analysed using Arsenazo III Method on ADVIA $^{\circledR} 2400$ Clinical Chemistry System Siemens Healthcare GmbH, Germany. Vitamin D deficiency was defined as 
total 25(OH)D <50nmol/L (IOM 2011, Bischoff-Ferrari et al., 2006).

\section{Power and sample size calculation}

Sample size was computed using the formula $\mathrm{n}=\left[\sigma^{2}\left(z_{1-\beta}+z_{1-\alpha / 2}\right)^{2}\right] /\left(\mu_{0}-\mu_{1}\right)^{2}$ (Rosner \& Glynn, 2011), in which $z_{1-\alpha / 2}=$ $1.96(5 \%$ of type 1 error $) ; z_{1-\beta}=0.84$ (a power of $80 \%) ; \mu_{0}=$ population mean; $\mu_{1}$ $=$ expected mean of study population; $\mathrm{n}=$ sample size of study population; $\sigma$ $=$ standard deviation $(S D)$ of reference population.

To estimate the average total $25(\mathrm{OH})$ D levels in postmenopausal Malaysian women, with a mean value (SD) of 44.4(10.6) nmol/L (Rahman et al., 2004), and a threshold of $<50 \mathrm{nmol} / \mathrm{L}$ for total $25(\mathrm{OH}) \mathrm{D}$ levels indicating vitamin $\mathrm{D}$ deficiency; 28 participants were required for this study to reach a significance level of $5 \%\left(z_{1-\alpha / 2}=1.96\right)$ and power of $80 \%$ $\left(z_{1-\beta}=0.84\right)$. Assuming an attrition rate of $20 \%, 34$ participants were estimated to be enrolled in this study.

\section{Data analysis}

Data were expressed as mean \pm standard error (SE) or frequency (percentage). The normality of distribution was checked for all study parameters. The number of adverse body composition indicators was categorised as 0 (normal; without low bone mass, low muscle mass, or high percent body fat), 1 (having any one of the components), 2 (having any two of the components), and 3 (OSO; having all three components).

Chi-square test was performed to assess the differences in categorical variables between the groups. One-way analysis of covariance (ANCOVA) was performed to assess the relationship effects between the number of adverse body composition indicators and anthropometric parameters, bonerelated parameters, blood biomarkers, and functional capacity tests, after adjusting for covariates. Adjustments for covariates like age, height, BMI, ethnicity, physical activity level, daily servings of milk, use of sunscreen, consumption of calcium and vitamin D supplements, were applied where appropriate.

Receiver operating characteristic (ROC) curve was constructed to determine the total 25(OH)D level (single inflection point based on the point closest to 0,1 corner of the ROC plane) to predict OSO (Perkins \& Schisterman, 2006). A statistical probability level of $p<0.05$ (two-sided) was considered significant. Statistical analyses were performed using the Statistical Package for Social Sciences (SPSS Version 25.0).

\section{RESULTS}

A total of 117 participants participated in this study. Regarding the number of adverse body composition indicators, $3 \%$ had none, $22 \%$ had one, $65 \%$ had two, and $10 \%$ had all three criteria (categorised as OSO). The prevalence of vitamin D deficiency (total $25(\mathrm{OH}$ ) $\mathrm{D}<50 \mathrm{nmol} / \mathrm{L})$ was $47 \%$ in our study population (Table 3 ).

Table 1 presents the relationship between the number of adverse body composition indicators and general characteristics. Physical activity level, milk intake, use of sunscreen, and consumption of calcium and vitamin D supplements are presented. Significant associations were found between the number of adverse body composition indicators with ethnic groups $(p=0.022)$ and vitamin D supplementation $(p=0.039)$. These variables were adjusted as covariates in the following analysis.

The relationship between the number of adverse body composition indicators and anthropometric parameters, bonerelated parameters, blood biomarkers, and functional capacity tests are presented in Table 2. Adjustments for covariates like age, height, BMI, ethnicity, physical activity level, daily 
Table 1. Comparison between the number of adverse body composition indicators and general characteristics

\begin{tabular}{|c|c|c|c|c|c|c|}
\hline Variables & $\begin{array}{c}\text { Overall } \\
\text { mean } \\
(n=117)\end{array}$ & $\begin{array}{c}0 \\
(n=4)\end{array}$ & $\begin{array}{c}1 \\
(n=26)\end{array}$ & $\begin{array}{c}2 \\
(n=76)\end{array}$ & $\begin{array}{c}3 \\
(n=11)\end{array}$ & p-value \\
\hline \multicolumn{7}{|l|}{ Ethnicity, $n(\%)$} \\
\hline Chinese & 47 (40.2) & $1(25.0)$ & $6(23.1)$ & $36(47.4)$ & $4(36.4)$ & $0.022^{*}$ \\
\hline Malays & $34(29.0)$ & $3(75.0)$ & $13(50.0)$ & $14(18.4)$ & $4(36.4)$ & \\
\hline Indians & $36(30.8)$ & $0(0.0)$ & 7 (26.9) & $26(34.2)$ & $3(27.3)$ & \\
\hline \multicolumn{7}{|l|}{ Physical activity level, $n(\%)$} \\
\hline Sedentary/inactive & $57(48.7)$ & $1(25.0)$ & $11(42.3)$ & 39 (51.3) & $6(54.5)$ & 0.543 \\
\hline $\begin{array}{l}\text { At least } 10 \text { minutes/week of } \\
\text { moderate activity }\end{array}$ & $25(21.4)$ & $2(50.0)$ & $4(15.4)$ & 15 (19.7) & $4(36.4)$ & \\
\hline $\begin{array}{l}20-60 \text { minutes/week of } \\
\text { moderate activity }\end{array}$ & $16(13.7)$ & $0(0.0)$ & $5(19.2)$ & $10(13.2)$ & $1(9.1)$ & \\
\hline $\begin{array}{l}60-180 \text { minutes/week of } \\
\text { moderate activity }\end{array}$ & $11(9.4)$ & $0(0.0)$ & $3(11.5)$ & $8(10.5)$ & $0(0.0)$ & \\
\hline $\begin{array}{l}>180 \text { minutes/week of } \\
\text { moderate activity }\end{array}$ & $8(6.8)$ & $1(25.0)$ & $3(11.5)$ & $4(5.3)$ & $0(0.0)$ & \\
\hline \multicolumn{7}{|l|}{ Daily serving of milk, $n(\%)$} \\
\hline None & $86(73.5)$ & $3(75.0)$ & $18(69.2)$ & $56(73.7)$ & $9(81.8)$ & 0.302 \\
\hline 1 serving/day & $25(21.4)$ & $0(0.0)$ & $6(23.2)$ & $18(23.7)$ & $1(9.1)$ & \\
\hline 2 servings/day & $5(4.3)$ & $1(25.0)$ & $1(3.8)$ & $2(2.6)$ & $9(9.1)$ & \\
\hline 3 servings/day & $1(0.9)$ & $0(0.0)$ & $1(3.8)$ & $0(0.0)$ & $0(0.0)$ & \\
\hline \multicolumn{7}{|l|}{ Use of sunscreen, $n(\%)$} \\
\hline Yes & $39(3.3)$ & $2(50.0)$ & $8(30.8)$ & $25(32.9)$ & $4(36.4)$ & 0.890 \\
\hline No & $78(66.7)$ & $2(50.0)$ & $18(69.2)$ & $51(67.1)$ & 7 (63.6) & \\
\hline \multicolumn{7}{|l|}{$\begin{array}{l}\text { Consumption of calcium } \\
\text { supplementation, } n(\%)\end{array}$} \\
\hline Yes & $27(23.1)$ & $0(0.0)$ & $9(34.6)$ & $15(19.7)$ & $3(27.3)$ & 0.291 \\
\hline No & 90 (76.9) & $4(100)$ & $17(65.4)$ & $61(80.3)$ & $8(72.7)$ & \\
\hline \multicolumn{7}{|l|}{$\begin{array}{l}\text { Consumption of vitamin } \mathrm{D} \\
\text { supplementation, } n(\%)\end{array}$} \\
\hline Yes & $14(12.0)$ & $0(0.0)$ & $1(3.8)$ & $9(11.8)$ & $4(36.4)$ & $0.039 *$ \\
\hline No & $103(88.0)$ & $4(100)$ & $25(96.2)$ & $67(88.2)$ & 7 (63.6) & \\
\hline
\end{tabular}

${ }^{*} p<0.05$ was considered significant, based on chi-square test.

0 , had no; 1 , had one; 2 , had two; 3 , had all three adverse body composition indicators (low bone mass, low muscle mass, or high percent body fat).

servings of milk, use of sunscreen, and consumption of calcium and vitamin D supplements were applied where appropriate. Our results revealed that individuals with three adverse body composition indicators had significantly lower fat-free mass $(p=0.007)$, muscle mass $(p=0.004)$, and ASMMI $(p<0.001)$ compared to those with zero, one and two adverse body composition indicators. They also had significantly lower body weight $(p<0.001)$ and BMI $(p<0.001)$ compared to those with two adverse body composition indicators; and significantly lower height $(p=0.002)$ compared to those with no and one adverse body composition indicator. Individuals with one, two and three 


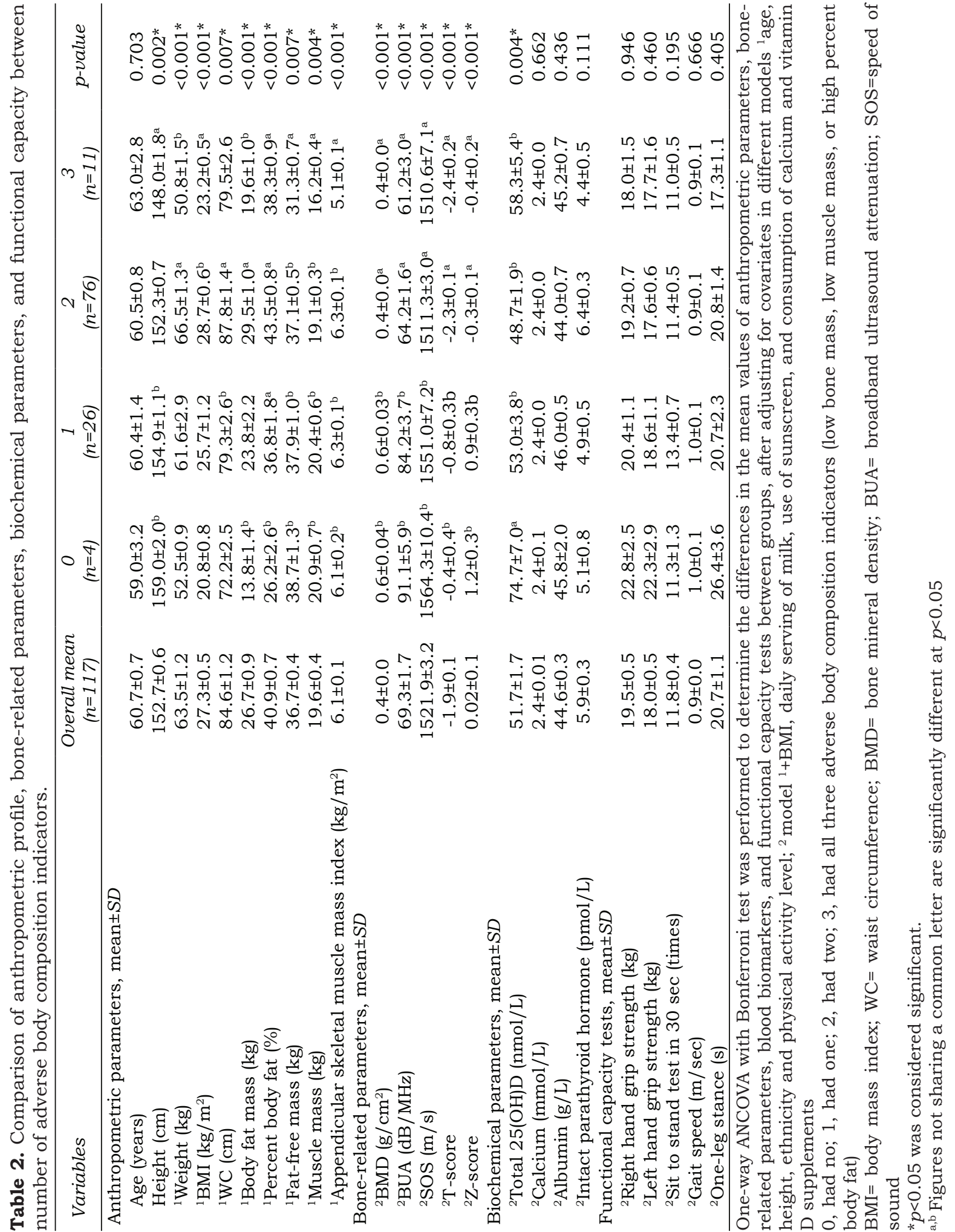


Table 3: Differences in mean values $( \pm \mathrm{SE})$ of anthropometric parameters, bone-related parameters, blood biomarkers, and functional capacity tests between vitamin $\mathrm{D}$ deficient and non-deficient groups

\begin{tabular}{|c|c|c|c|c|}
\hline Variables & $\begin{array}{l}\text { Optimal } \\
\text { cut off }\end{array}$ & $\begin{array}{c}\text { Vitamin D } \\
\text { deficient } \\
n=55\end{array}$ & $\begin{array}{c}\text { Vitamin } D \\
\text { non-deficient } \\
n=62\end{array}$ & p-value \\
\hline \multicolumn{5}{|l|}{ Anthropometric parameters } \\
\hline Age (years) & & $60.9 \pm 1.0$ & $60.5 \pm 0.9$ & 0.820 \\
\hline Height $(\mathrm{cm})$ & & $151.3 \pm 0.9$ & $154.0 \pm 0.7$ & $0.019 *$ \\
\hline${ }^{1}$ Weight (kg) & & $65.6 \pm 1.9$ & $61.6 \pm 1.4$ & 0.077 \\
\hline${ }^{1} \mathrm{BMI}\left(\mathrm{kg} / \mathrm{m}^{2}\right)$ & & $28.7 \pm 0.8$ & $26.0 \pm 0.6$ & 0.086 \\
\hline${ }^{1} \mathrm{WC}(\mathrm{cm})$ & & $85.2 \pm 1.8$ & $84.1 \pm 1.6$ & 0.921 \\
\hline${ }^{1}$ Body fat mass (kg) & & $29.2 \pm 1.4$ & $24.7 \pm 1.1$ & $0.047^{*}$ \\
\hline${ }^{1}$ Percent body fat $(\%)$ & & $43.2 \pm 1.0$ & $38.8 \pm 1.0$ & 0.052 \\
\hline${ }^{1}$ Fat-free mass $(\mathrm{kg})$ & & $36.5 \pm 0.7$ & $37.0 \pm 0.6$ & 0.424 \\
\hline${ }^{1}$ Muscle mass (kg) & & $19.5 \pm 0.4$ & $19.8 \pm 0.3$ & 0.470 \\
\hline $\begin{array}{l}{ }^{1} \text { Appendicular skeletal muscle mass } \\
\text { index }\left(\mathrm{kg} / \mathrm{m}^{2}\right)\end{array}$ & & $6.2 \pm 0.1$ & $6.1 \pm 0.1$ & 0.397 \\
\hline \multicolumn{5}{|l|}{ Bone-related parameters } \\
\hline${ }^{2} \mathrm{BMD}\left(\mathrm{g} / \mathrm{cm}^{2}\right)$ & & $0.4 \pm 0.02$ & $0.5 \pm 0.02$ & 0.900 \\
\hline${ }^{2} \mathrm{BUA}(\mathrm{dB} / \mathrm{MHz})$ & & $67.4 \pm 2.7$ & $70.6 \pm 2.1$ & 0.813 \\
\hline${ }^{2} \mathrm{SOS}(\mathrm{m} / \mathrm{s})$ & & $1517.0 \pm 5.3$ & $1525.5 \pm 3.9$ & 0.949 \\
\hline${ }^{2} \mathrm{~T}$-score & & $-2.1 \pm 0.2$ & $-1.9 \pm 0.2$ & 0.782 \\
\hline${ }^{2} Z$-score & & $-0.1 \pm 0.2$ & $0.1 \pm 0.1$ & 0.798 \\
\hline \multicolumn{5}{|l|}{ Biochemical parameters } \\
\hline${ }^{2}$ Total $25(\mathrm{OH}) \mathrm{D}(\mathrm{nmol} / \mathrm{L})$ & $50^{\mathrm{a}}$ & $36.8 \pm 1.2^{+}$ & $64.9 \pm 1.7^{+}$ & $<0.001^{*}$ \\
\hline${ }^{2}$ Calcium (mmol/L) & & $2.4 \pm 0.02$ & $2.4 \pm 0.01$ & 0.636 \\
\hline${ }^{2} \operatorname{Albumin}(\mathrm{g} / \mathrm{L})$ & & $44.7 \pm 0.3$ & $44.6 \pm 0.4$ & 0.449 \\
\hline${ }^{2}$ Intact Parathyroid hormone (pmol/L) & $4.2^{\mathrm{b}}$ & $7.2 \pm 0.4^{+}$ & $3.8 \pm 0.3$ & $<0.001^{*}$ \\
\hline \multicolumn{5}{|l|}{ Functional capacity tests } \\
\hline${ }^{2}$ Right hand grip strength $(\mathrm{kg})$ & $18^{\mathrm{c}}$ & $18.5 \pm 0.8$ & $20.4 \pm 0.7^{+}$ & 0.077 \\
\hline${ }^{2}$ Left hand grip strength $(\mathrm{kg})$ & $18^{\mathrm{c}}$ & $16.9 \pm 0.7$ & $19.0 \pm 0.6$ & $0.037^{*}$ \\
\hline${ }^{2}$ Sit to stand test in $30 \mathrm{sec}$ (times) & & $11.4 \pm 0.5$ & $12.1 \pm 0.5$ & 0.665 \\
\hline${ }^{2}$ Gait speed (m/sec) & $0.8^{c}$ & $0.9 \pm 0.04$ & $1.0 \pm 0.04^{+}$ & 0.116 \\
\hline${ }^{2}$ One-leg stance (s) & & $19.2 \pm 1.8$ & $21.7 \pm 1.3$ & 0.492 \\
\hline
\end{tabular}

Vitamin D deficiency was defined as total 25OHD Vitamin D <50nmol/L (Bischoff-Ferrari et al., 2006).

One-way ANCOVA was performed to determine the differences in the mean values of anthropometric parameters, bone-related parameters, blood biomarkers, and functional capacity tests between different vitamin D deficient and non-deficient groups, after adjusting for covariates in different models ${ }^{1}$ age, height, ethnicity and physical activity level; ${ }^{2}$ model $1+$ BMI, fat mass, muscle mass, percent body fat, fat-free mass, daily serving of milk, use of sunscreen, and consumption of calcium and vitamin D supplements

$\mathrm{BMI}=$ body mass index; $\mathrm{WC}=$ waist circumference; $\mathrm{BMD}=$ bone mineral density; $\mathrm{BUA}=$ broadband ultrasound attenuation; $\mathrm{SOS}=$ speed of sound

${ }^{a}$ Bischoff-Ferrari et al. (2006)

${ }^{\mathrm{b}}$ Holick et al. (2012)

${ }^{c}$ AWGS (Chen et al., 2014)

${ }^{*} p<0.05$ was considered significant

${ }^{+} p<0.05$ was considered significantly different compared to the respective cut-off values, based on one-sample $t$-test 
adverse body composition indicators had significantly higher percent body fat compared to those with no adverse body composition indicator.

With respect to bone-related parameters, individuals with two and three adverse body composition indicators had significantly lower BMD $(p<0.001)$, BUA $(p<0.001)$, SOS $(p<0.001)$, T-score $(p<0.001)$, and $Z$-score $(p<0.001)$ compared to individuals with no and one adverse body composition indicator. Moreover, individuals without any adverse body composition indicator had significantly higher total 25(OH)D $\quad(74.7 \pm 7.0 \mathrm{nmol} / \mathrm{L}, \quad p=0.004)$ compared to all the other groups of one $(50.0 \pm 3.8 \mathrm{nmol} / \mathrm{L})$, two $(48.7 \pm 1.9 \mathrm{nmol} / \mathrm{L})$, and all three $(58.3 \pm 5.4 \mathrm{nmol} / \mathrm{L})$ adverse body composition indicators.

Participants were categorised into vitamin $\mathrm{D}$ deficient and non-deficient groups (vitamin $\mathrm{D}$ deficiency defined as total 25(OH)D <50nmol/L) (BischoffFerrari et al., 2006). The differences in the mean values of anthropometric parameters, bone-related parameters, blood biomarkers, and functional capacity tests between the vitamin D deficient and non-deficient groups are reported in Table 3. Forty-seven percent $(47 \%, n=55)$ of the participants were vitamin $\mathrm{D}$ deficient. The analysis revealed that the vitamin $\mathrm{D}$ deficient group had significantly lower height ( $p=0.019)$, left hand grip strength $(p=0.037)$, and total 25(OH)D $(p<0.001)$, but significantly higher fat mass $(p=0.047)$ compared to the non-deficient group, after adjusting for covariates. Moreover, non-vitamin D deficient group had significantly higher right hand grip strength and gait speed compared to the respective cut-off values for diagnosing sarcopenia (Chen et al., 2014) $(<18 \mathrm{~kg}$ and $<0.8 \mathrm{~m} / \mathrm{s}$, respectively) $(p<0.05)$. However, such differences were not found in the vitamin $\mathrm{D}$ deficient group $(p>0.05)$.
Figure 1 illustrates that the area under the curve (AUC) was $0.683(95 \%$ $\mathrm{CI}=0.500-0.867, p=0.04)$. The single inflection point (optimal level of total 25 $(\mathrm{OH}) \mathrm{D}$ in predicting $\mathrm{OSO}$ based on the point closest to the $(0,1)$ corner of the ROC plane) with a maximum sensitivity of 0.727 and specificity of 0.723 was $58.9 \mathrm{nmol} / \mathrm{L}$.

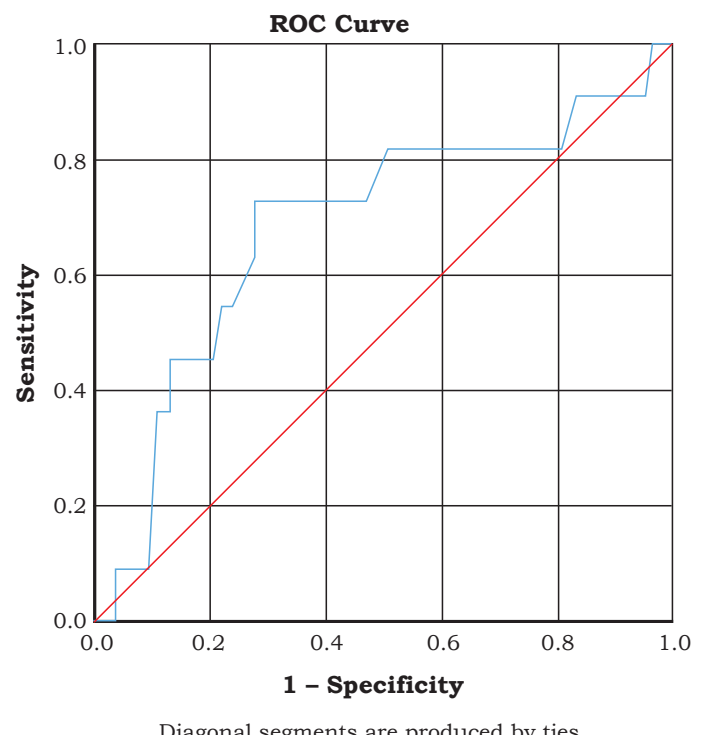

Figure 1. ROC curve for identifying optimal total $25(\mathrm{OH}) \mathrm{D}$ cut-off point in predicting osteosarcopenia obesity (OSO)

'Osteosarcopenia obesity' was defined as $\mathrm{T}$-score $\leq-1.0$, Appendicular skeletal muscle mass index $\leq 5.41 \mathrm{~kg} / \mathrm{m}^{2}\left(20^{\text {th }}\right.$ percentile of ASMMI of the study population), body fat percentage $\geq 32 \%$ (Ilich et al., 2016). Number of participants with OSO $=11(10 \%)$.

\section{DISCUSSION}

\section{Vitamin $D$ and bone}

The results from the present study revealed a high prevalence of vitamin D deficiency and secondary hyperparathyroidism in the study population. With $50 \mathrm{nmols} / \mathrm{L}$ as the threshold value, $47 \%$ of the current 
population was found to be vitamin D deficient. The mean iPTH levels of these individuals was significantly higher than the non-deficient group, which was also significantly higher than the threshold for defining secondary hyperparathyroidism based on intact PTH $>40 \mathrm{pg} / \mathrm{ml}$ (4.2 pmol/L) (Holick et al., 2012)) (Table 3). Declining levels of $25(\mathrm{OH}) \mathrm{D}$ are associated with a rise in iPTH levels, which may have adverse effects on the skeleton. However, the level of $25(\mathrm{OH}) \mathrm{D}$ at which this occurs may differ in population groups. The overall mean value of BUA of the study participants was $69.3 \pm 1.7 \mathrm{~dB} / \mathrm{MHz}$ (Table 2). This BUA value is comparable and in fact, even higher than the average BUA of age-matched and ethnically similar healthy reference females at $62.34 \mathrm{~dB} / \mathrm{MHz}$ (Lim, Chan \& Lam, 2005). Interestingly, BUA of participants identified as vitamin $D$ deficient was close to the reference value at $67.4 \pm 2.7$ $\mathrm{dB} / \mathrm{MHz}$ (Lim et al., 2005). Lowe et al. (2010) reported that the South Asian postmenopausal women in their study had significantly higher serum iPTH and lower 25(OH)D concentrations than their Caucasian counterparts, however, this was not associated with significantly higher markers of bone resorption or reduced bone quality (Lowe et al., 2010).

African Americans, who have lower levels of vitamin D compared to other American groups, have adaptive responses to low $25(\mathrm{OH}) \mathrm{D}$, that may reduce the harmful effects of low $25(\mathrm{OH})$ $\mathrm{D}$ on bone (Harris, 2006). There is evidence that blacks may have intestinal resistance to the actions of $1,25(\mathrm{OH})$ $\mathrm{D}$ (Dawson-Hughes et al., 1995). This is relevant for bone health as $1,25(\mathrm{OH})$ $\mathrm{D}$ may have favourable effects on bone formation that are independent of its effect on increasing calcium absorption. Another adaptive response may be skeletal resistance to iPTH stimulated bone resorption (Cosman et al., 1997).
Therefore, in terms of bone health, the level of vitamin $\mathrm{D}$, which poses a threat to bone health, may vary in different ethnic groups. The current study participants were overweight, with an average BMI of $27.3 \pm 0.5 \mathrm{~kg} / \mathrm{m}^{2}$ and percent body fat $40.9 \pm 0.7$. It is suggested that adverse skeletal effects of low levels of $25(\mathrm{OH}) \mathrm{D}$ may have been counteracted by positive skeletal effects of increased oestrogen synthesis from adipocyte aromatase or adipocyte leptin secretion (Walsh et al., 2016).

\section{Functional capacity of study participants}

It is to be noted that left hand grip strength was significantly higher in the non-vitamin D deficient group $(19.0 \pm 0.6$ vs. $16.9 \pm 0.7, \quad p=0.037)$. Although not statistically significant, all other functional capacity scores were also higher in the non-vitamin $\mathrm{D}$ deficient group compared to the deficient group. A greater muscle gain was found in patients with a higher baseline of serum $25-(\mathrm{OH})$ vitamin D in the PROVIDE study (Verlaan et al., 2018). The authors suggested that the mechanism of muscle gain via $25(\mathrm{OH})$ $\mathrm{D}$ may be explained by synergistic action of vitamin $\mathrm{D}$ with leucine and insulin to stimulate muscle protein synthesis. Furthermore, a higher dose of vitamin $\mathrm{D}$ or longer supplementation to achieve serum 25(OH)D concentrations of 20 to 40 micrograms/L (50-100nmol/L) has been suggested to increase muscle mass (Verlaan et al., 2018). The average serum $25(\mathrm{OH}) \mathrm{D}$ concentrations of the vitamin $\mathrm{D}$ deficient group in the current study was $36.8 \pm 1.2 \mathrm{nmol} / \mathrm{L}$. The current study has arrived at the threshold level of $58.9 \mathrm{nmol} / \mathrm{L}$, below which the study participants are at risk of suffering from OSO. Data presented in Table 3 clearly indicated that the vitamin $\mathrm{D}$ deficient group, with average 25(OH)D levels of $36.8 \pm 1.2 \mathrm{nmol} / \mathrm{L}$ (significantly lower than $58.9 \mathrm{nmol} / \mathrm{L}$ ) were compromised 
with respect to their functional capacity performance. This study therefore highlights that timely intervention to upgrade vitamin D status in the study population is necessary. With age, loss of lower limb power and limb strength may inevitably increase the risk of falls, injury and disability (Nevitt et al., 1989).

\section{Muscle and fat}

The results from the current study showed that $10 \%$ of the study participants were with OSO. This is of concern as this condition is generally without pain yet progressively degenerative. This calls for strategies to be in place for screening and timely intervention. Authors of earlier studies have proposed possible mechanisms that lead to progressive losses of bone and muscle mass with increase in adipose tissue. As reported earlier in the text, increase in adiposity is correlated with loss of skeletal muscle function and size (sarcopenia). The consequence of sarcopenia is the loss of skeletal contractile power, particularly in the lower limb, which is essential for rising from a chair or climbing up stairs. In the current population, non-vitamin D deficient group had significantly higher right handgrip strength and gait speed compared to the respective cutoff values for diagnosing sarcopenia $(<18 \mathrm{~kg}$ and $<0.8 \mathrm{~m} / \mathrm{s}$, respectively) (Chen et al., 2014). Loss of lower limb power and strength is the greatest risk factor for falls, injury and disability (Moreland et al., 2004; Nevitt et al., 1989). About $8 \%$ of muscle mass is lost per decade between the ages of 40 and 70, and this progresses to about $15 \%$ per decade after 70 years of age. Moreover, with age, there is an increase in lipid content and direct deposition of lipids within the muscle fibres (Visser et al., 2005).

This study has identified that at least in the current population, a minimum level of $58.9 \mathrm{nmol} / \mathrm{L}$ of $25(\mathrm{OH})$ $\mathrm{D}$ is necessary to prevent the risk for the occurrence of osteosarcopenia in the participants. The Malaysian population will reach the status of an 'ageing' nation by 2030. Prevention of debilitating disorders of motor functions, such as OSO, is no doubt the best way to counter this social and economic burden. Simple diagnostics, as reported in the current study in asymptomatic women could reduce the risk of adverse health outcomes at a later age and pave the way for better mobility among free-living individuals of any community.

\section{Strengths}

This was the first study that investigated OSO in a group of postmenopausal Malaysian women. This study reports muscle mass, as well as muscle performance via grip strength measurements and SPPB test. Furthermore, this study has arrived at a threshold level of $58.9 \mathrm{nmol} / \mathrm{L}$ for $25(\mathrm{OH}) \mathrm{D}$, below which participants will be considered at risk of OSO. This study also classified participants on the phenotypic debilities of bone, muscle and physical performance based on established and published thresholds.

\section{Limitations}

The sample size of the study was comparatively small. This may have limited the outcome of the ROC curve analysis. Bone health was assessed by ultrasound and body composition by BIA. Although dual-energy x-ray absorptiometry (DXA) is considered the "gold standard" test for BMD determination, it is not widely available in primary care, thus using it as a screening tool at primary settings is not feasible due to constraints of resources. There is an increasing body of evidence demonstrating that low ultrasound readings at the calcaneus are associated with increased fracture risk and correlate well with DXA in postmenopausal women (Cook et al., 
2005). Portable ultrasound devices, such as the one used in this study, are relatively inexpensive and easy to operate within the primary care setting and can be used to screen patients with low bone density for further investigation (Evans et al., 2005; Lee et al., 2006). There are reports that sunscreen use may increase the risk of vitamin D deficiency. Therefore, we collected information on the use of sunscreen in our participants to assess, whether there were any significant differences between the groups with adverse body composition indicators (Table 1). No significant difference was found on the latter criterion. Furthermore, for the same reason, 'use of sunscreen' was included as a covariate and adjusted for in data analysis. Another limitation of this study is that no information was collected on sunshine exposure and skin type.

\section{CONCLUSION}

The study participants had an average BUA higher than the average BUA of agematched and ethnically similar healthy reference females. Increased serum vitamin D levels were associated with lower body fat, enhanced bone quality, and improved functional capacity of the postmenopausal women in this study. Approximately half of the participants were vitamin $\mathrm{D}$ deficient. The average serum 25(OH)D concentration of the vitamin $\mathrm{D}$ deficient group in the current study was $36.8 \pm 1.2 \mathrm{nmol} / \mathrm{L}$, which is considerably lower than the threshold of $50 \mathrm{nmol} / \mathrm{L}$ and the threshold of $58.9 \mathrm{nmol} / \mathrm{L}$ for predicting OSO. Therefore, maintaining serum vitamin D levels above $>58.9 \mathrm{nmol} / \mathrm{L}$ (at least in postmenopausal Malaysian women) may protect them against the combined abnormalities of bone, muscle and body composition in mid- and later life. This study identified $10 \%$ of the study participants with OSO. Screening for OSO with simple diagnostics (as reported in the current study) in asymptomatic obese women could reduce the risk of adverse health outcomes at a later age and pave the way for better mobility among ageing individuals. Populationspecific thresholds for total $25(\mathrm{OH}) \mathrm{D}$ should be arrived at in order to screen for specific diseases where vitamin D deficiency is incriminated.

\section{List of abbreviations}

ANCOVA, analysis of covariance; ASMMI, appendicular skeletal muscle mass index; BIA, bioelectrical impedance analysis; BMD, bone mineral density; BMI, body mass index, BUA, broadband ultrasound attenuation; DEXA, dual-energy x-ray absorptiometry; VDBP, vitamin D binding protein; 25(OH)vitamin D, 25-hydroxyvitamin D; OSO, osteosarcopenic obesity; iPTH, intact parathyroid hormone; ROC, receiver operating characteristic curve; $\mathrm{SE}$, standard error of mean; SOS, speed of sound; SPPB, short physical performance battery; WC, waist circumference; WHR, waist-hip-ratio.

\section{Acknowledgements}

The authors would like to thank the participants for their time and support to this study. The authors thank Dr Weang Ke Ho for her advice on statistical analysis. The authors are grateful to Pui Yee Tan who helped with the data analysis. The authors extend their gratitude to the staff of the diagnostic centre for assistance with blood analysis. This study was funded by internal grants from the University of Nottingham Malaysia.

\section{Authors' contributions}

MSR, designed the study, was responsible for recruitment of the participants, analysed the data and wrote the paper; ANZ, designed the study, was responsible for recruitment of the participants, collected and analysed the data.

\section{Conflict of interest}

The authors do not have any conflict of interest to report. The lead author affirms that this manuscript is an honest, accurate, and transparent account of the study being reported. The reporting of this work is in compliance with the STROBE guidelines. 


\section{References}

Aguilar-Farias N (2016). Objective and subjective methods for measuring physical activity and sedentary behaviour in older adults. PhD Thesis. School of Human Movement and Nutrition Sciences, The University of Queensland. From https://core.ac.uk/download/pdf/43394112. pdf [Retrieved July 26 2017].

Bischoff-Ferrari HA, Giovannucci E, Willett WC, Dietrich T \& Dawson-Hughes B (2006). Estimation of optimal serum concentrations of 25(OH)D for multiple health outcomes. Am J Clin Nutr 84:18-28.

Chen LK, Liu LK, Woo J, Assantachai P, Auyeung TW, Bahyah KS, Chou MY, Chen LY, Hsu PS, Krairit O, Lee JSW, Lee WJ, Lee Y, Liang CK, Limpawattana P, Lin CS, Peng LN, Satake S, Suzuki T, Won CW, Wu CH, Wu SN, Zhang T, Zeng P, Akishita M \& Arai H (2014). Sarcopenia in Asia: Consensus report of the Asian working group for sarcopenia. J Am Med Dir Assoc 15:95-101.

Cook RB, Collins D, Tucker J \& Zioupos P (2005). Comparison of questionnaire and quantitative ultrasound techniques as screening tools for DXA. Osteoporos Int 16:1565-1575.

Evans WJ (1995). What Is Sarcopenia? J Gerontol A Biol Sci Med Sci 50A:5-8.4.

Fukagawa NK, Bandini LG \& Young JB (2017). Effect of age on body composition and resting metabolic rate. Am J Physiol Metab 259:E233238.

Glerup H, Mikkelsen K, Poulsen L, Hass E, Overbeck S, Andersen H, Charles P \& Eriksen EF (2000). Hypovitaminosis D myopathy without biochemical signs of osteomalacic bone involvement. Calcif Tissue Int 66:419-424.

Gunton JE, Girgis CM, Baldock PA \& Lips P (2015). Bone muscle interactions and vitamin D. Bone 80:89-94.

Han SS, Kim M, Lee SM, Lee JP, Kim S, Joo KW, Lim CS, Kim YS \& Kim DK (2014). Association between body fat and vitamin D status in Korean adults. Asia Pac J Clin Nutr 23:65-75.

Harris SS. (2006). Vitamin D and African Americans. J Nutr 136:1126-1129.

Holick MF, Binkley NC, Bischoff-Ferrari HA, Gordon CM, Hanley DA, Heaney RP, Murad MH \& Weaver CM (2012). Guidelines for preventing and treating vitamin D deficiency and insufficiency revisited. $J$ Clin Endocrinol Metab 2012 97:153-1158.
Institute of Medicine. Dietary Reference Intakes for Calcium and Vitamin D. The National Academic Press USA of Medicine: Washington, DC, USA, 2011

Ilich JZ, Kelly OJ, Inglis JE, Panton LB, Duque G \& Ormsbee MJ (2014). Interrelationship among muscle, fat, and bone: Connecting the dots on cellular, hormonal, and whole body levels. Aging Res Rev 15:51-60.

Ilich JZ, Kelly OJ \& Inglis JE (2016). Osteosarcopenic obesity syndrome: what is it and how can it be identified and diagnosed? Curr Gerontol Geriatr Res :7325973.

Issa R \& Griffin T (2012). Pathobiology of obesity and osteoarthritis: integrating biomechanics and inflammation. Pathobiol Aging Age-related Dis 2:17470.

Larsson L, Grimby G \& Karlsson J (2017). Muscle strength and speed of movement in relation to age and muscle morphology. J Appl Physiol 46:451-456.

Lee M, Czerwinski SA, Choh AC, Demerath EW, Sun SS, Chumlea WC, Towne B \& Siervogel RM (2016). Unique and common genetic effects between bone mineral density and calcaneal quantitative ultrasound measures: The Fels Longitudinal Study. Osteoporos Int 17:865-71.

Lim YW, Chan L \& Lam KS. (2005). Broadband ultrasound attenuation reference database for Southeast Asian males and females. Ann Acad Med Singapore 34:545-547.

Lowe NM, Mitra SR, Foster PC, Bhojani I \& McCann JF (2010). Vitamin D status and markers of bone turnover in Caucasian and South Asian postmenopausal women living in the UK. $\mathrm{Br} J$ Nutr 103:1706-10.

Moreland JD, Richardson JA, Goldsmith $\mathrm{CH}$ \& Clase CM (2004). Muscle weakness and falls in older adults: a systematic review and metaanalysis. J Am Geriatr Soc 52:1121-1129.

Nevitt MC, Cummings SR, Kidd S \& Black D (1989). Risk factors for recurrent nonsyncopal falls: a prospective study. JAMA 261:2663-2668.

Novak LP (1972). Aging, total body potassium, fatfree mass, and cell mass in males and females between ages 18 and 85 years. $J$ Gerontol 27:438-443.

Ormsbee MJ, Prado CM, Ilich JZ, Purcell S, Siervo M, Folsom A \& Panton L (2014). Osteosarcopenic obesity: the role of bone, muscle, and fat on health. J Cachexia Sarcopenia Muscle 5:183192 . 
Perkins NJ \& Schisterman EF (2006). The inconsistency of "optimal" cut-points using two ROC based criteria. Am J Epidemiol 163:670-5.

Rosner B \& Glynn RJ (2011). Power and sample size estimation for the clustered wilcoxon test. Biometrics 67:645-653.

Shin H, Liu PY, Panton LB \& Ilich JZ (2014). Physical performance in relation to body composition and bone mineral density in healthy, overweight, and obese postmenopausal women. J Geriatr Phys Ther 37:7-16.

The North American Menopause Society (2005). Menopause Health Questionnaire. From https://www.menopause.org/docs/ default-document-library/questionnaire. pdf?sfvrsn=90fd425b_0 [Retrieved August 26 2017]

Verlaan S, Maier AB, Bauer JM, Bautmans I, Brandt K, Donini LM, Maggio M, McMurdo MET, Mets T, Seal C, Wijers SLJ, Sieber C, Boirie Y \& Cederholm T (2018). Sufficient levels of $25(\mathrm{OH}) \mathrm{D}$ and protein intake required to increase muscle mass in sarcopenic older adults - The PROVIDE study. Clin Nutr 37:551557.
Visser M, Goodpaster BH, Kritchevsky SB, Newman AB, Nevitt M, Rubin SM, Simonsick EM \& Harris TB (2005). Muscle mass, muscle strength, and muscle fat infiltration as predictors of incident mobility limitations in well-functioning older persons. $J$ Gerontol A Biol Sci Med Sci 60:324-333.

Walsh JS, Evans AL, Bowles S, Naylor KE, Jones KS, Schoenmakers I, Jacques RM \& Eastell $R$ (2016). Free 25(OH)D is low in obesity, but there are no adverse associations with bone health. Am J Clin Nutr 103:1465-1471. 